\title{
Potencial fisiológico de diásporos de Tectona grandis L.f. derrubados pelo vento
}

\author{
Sidney Fernando CALDEIRA ${ }^{1}$, Maria Cristina de Figueiredo e ALBUQUERQUE² \\ RESUMO \\ Nas áreas de produção de sementes de Tectona grandis em Cáceres, MT, ventos fortes podem causar queda precoce de frutos. \\ Diásporos de três lotes de teca, um obtido após a queda natural e os outros dois após queda precoce, foram inicialmente \\ qualificados quanto ao teor de água, massa de mil diásporos, número de diásporos por quilograma, emergência em canteiro \\ e respectivo tempo médio. Essas duas últimas variáveis foram novamente determinadas em intervalos de 50 dias até 331 dias \\ após a colheita com o uso de 200 diásporos divididos em quatro repetiçóes. Para os diásporos de queda natural, a emergência \\ de plântulas e o tempo médio náo diferiram nos períodos de análise com média geral de 60,6\% e 10,8 dias. Os diásporos \\ dos lotes de colheita precoce apresentaram a emergência inicial de 23,5 e $17,5 \%$ e os tempos médios de 19,4 e 22,6 dias, \\ respectivamente. Até 115 dias após a colheita, a emergência aumentou $(55,5$ e 59,5\%) e o tempo médio diminuiu (15,0 e \\ 14,1 dias) e a partir daí ocorreu o inverso. Os diásporos de colheita precoce derrubados pelo vento apresentam maturação e o \\ maior potencial fisiológico aos 115 dias após a colheita. No período de 64 a 269 dias após a colheita, esses diásporos atingem \\ o padrão mínimo estabelecido para a teca e o período entre 115 a 165 dias é o mais adequado para sua utilização.
}

PALAVRAS-CHAVE: Colheita precoce, Maturação, Emergência, Teca.

\section{Physiological potential of diasporas of Tectona grandis L.f. felled by wind}

\section{ABSTRACT}

In the seed production areas of Tectona grandis in Cáceres, state of Mato Grosso, Brazil, strong winds cause the precocious fall of fruits. Diasporas of three lots of teak, one of then crop after the natural fall, and the others two after the precocious fall were characterized initially by the content of water, thousand diasporas mass, number of diasporas by kilogram, emergency in seedbeds and respective average time. With 200 diasporas divided in four replications and in periods of 50 days until 331 days after crop, the last two variables were determined again. To the diasporas of natural fall, the seedlings emergency and the average time were not different in periods of analyses with a general average of $60.6 \%$ and 10.8 days. The diasporas of the precocious crop lots presented respectively the initial emergency of 23.5 and $17.5 \%$ and the average time of 19.4 and 22.6 days. Until 115 days after crop, the emergency increased (55.5 and 59.5\%) and the average time diminished (15.0 and 14.1 days) and on this point the inverse occurred. The diasporas of precocious crop fall by the wind present maturation and the greater physiological potential at 115 days after the crop. In the period at 64 to 269 days after crop, these diasporas reaches the established minimum standard for the teak and at 115 to 165 days is more adjusted period for its use.

KEYWORDS: Precocious crop, Emergency, Maturation, Teak.

1 Universidade Federal de Mato Grosso - UFMT, E-mail: sidcal@ufmt.br

${ }^{2}$ Universidade Federal de Mato Grosso - UFMT, E-mail: mariacfa@terra.com.br 


\section{INTRODUÇÃO}

A Tectona grandis L.f., teca, com 48.526 ha de povoamentos implantados é a espécie mais plantada em Mato Grosso, o que corresponde a $33 \%$ da área reflorestada, contra $31 \%$ de seringueira e um total de $31 \%$ com eucaliptos, principalmente o híbrido "urograndis" e as espécies E. citriodora e $E$. camaldulensis (Shimizu et al., 2007). Dentre essas espécies, teca é a única que poderá atender a indústria madeireira do Estado, face às restriçôes relacionadas com a exploração das florestas autóctones.

A teca está entre as poucas espécies florestais contempladas nas Regras para Análise de Sementes (Brasil, 1992). Além disso, em Mato Grosso foi estabelecido o padrão para produção de mudas (Brasil, 1998a) e de sementes fiscalizadas dessa espécie (Brasil, 1998b), onde as áreas de produção de sementes (APS) devem ter, no mínimo, 15 anos de idade e os lotes devem possuir no máximo de $1.000 \mathrm{~kg}$ de frutos. Os frutos dessa espécie são utilizados como unidades de dispersão, devido a dureza de seu mesocarpo e da presença de sementes muito pequenas, sensíveis e de difícil extraçáo (Kaosa-Ard, 1986), sendo tal fato comum em diversas espécies florestais (Figliolia et al., 1993).

Considerando os valores de área reflorestada apresentados por Shimizu et al. (2007), cerca de 2500 ha poderiam ser transformados em APS, sem considerar outros aspectos restritivos, como a faixa de isolamento de $500 \mathrm{~m}$ e a área mínima de 5 ha para se estabelecer uma APS. Em razão disso, a oferta de diásporos de teca em Mato Grosso é limitada. Também existem outros fatores que podem diminuir essa disponibilidade, como a baixa germinabilidade da espécie, cujo valor mínimo estabelecido no padrão para comercialização de lotes é 35\% (Brasil, 1998b).

O ponto de maturidade fisiológica representa, teoricamente, o ponto em que a semente atinge o máximo de massa seca, vigor e germinação. A partir desse momento a semente não depende mais da planta para completar seu desenvolvimento, estando pronta para ser colhida, sendo esse ponto variável em função da espécie, das condiçóes climáticas e do próprio indivíduo (Carvalho e Nakagawa, 2000). A hipótese de que as sementes alcançariam a máxima qualidade ao atingirem o máximo de acúmulo de matéria seca e que, após esse ponto, a germinaçáo e o vigor declinariam, tem sido contestada (Guimarães et al., 1998). Assim sendo, Piña-Rodrigues e Aguiar (1993) consideraram que há a necessidade de estabelecer o índice de maturação que permita a definição da época adequada de colheita das sementes para cada espécie.

Caldeira et al. (2000) caracterizaram a qualidade de frutos oriundos de 13 lotes de teca de três APS no estado de Mato Grosso e registraram valores entre 29,7 a 70,8\% para emergência de plântulas. Os autores destacaram que o lote que apresentou $29,7 \%$ de emergência havia sido colhido um mês antes dos outros lotes, pois os diásporos haviam sido derrubados pela ação de ventos fortes, comuns na regiáo com o deslocamento de frentes frias. Assim, indicaram a possibilidade do baixo desempenho ser devido ao fato dos diásporos náo terem atingido a maturidade fisiológica, pois o segundo menor valor registrado foi de $45,3 \%$ e todos os demais lotes apresentaram resultados acima de $52 \%$ de emergência de plântulas. Piña-Rodrigues e Aguiar (1993) observaram que as espécies Carapa guianensis (andiroba), Brosimum lactescens (amapai) e Astronium gracile (aroeira) perdiam grande parte de seus frutos antes da maturação, devido provavelmente às condiçôes climáticas.

Nas APS em Cáceres-MT, de julho a outubro os frutos sáo colhidos e podem ser armazenados por vários meses, sem prejuízo para a sua viabilidade, desde que o local seja fresco e ao abrigo do sol e da luz (Cáceres Florestal, 1997). Caldeira et al. (2003) comprovaram que diásporos de teca coletados em Cáceres-MT e armazenados até 12 meses em ambiente de sala $\left(28^{\circ} \mathrm{C}\right.$ e $61,7 \%$ de umidade relativa, UR) mantém a sua qualidade e que períodos mais extensos exigem ambiente controlado por condicionador de ar $\left(19,1^{\circ} \mathrm{C}\right.$ e UR de $\left.67,7 \%\right)$. Esses resultados são semelhantes aos obtidos por Suangtho (2000) com diásporos da regiâo de Lampang na Tailândia.

O presente trabalho teve como objetivos verificar se ocorre variação do potencial fisiológico em diásporos de teca derrubados precocemente pela ação de intempéries, se esses diásporos atingem o padrão mínimo de germinabilidade estabelecido para comercializaçáo da espécie e se existe um período adequado para a sua utilização.

\section{MATERIAL E MÉTODOS}

Os frutos de teca (diásporos) utilizados neste trabalho foram originários de três lotes, cada um com $1.000 \mathrm{~kg}$, colhidos em uma área de produção de sementes (APS) da empresa Cáceres Florestal SA, localizada na Fazenda Paraguatuba, município de Cáceres-MT, em um paralelogramo irregular formado pelas coordenadas geográficas $15^{\circ} 54^{\prime} 36^{\prime \prime} \mathrm{S}, 57^{\circ} 39^{\prime} 41^{\prime \prime W}$ e $15^{\circ} 56^{\prime} 29^{\prime} \mathrm{S}, 57^{\circ} 40^{\prime} 38^{\prime} \mathrm{W}$. Segundo Musis (1997), a regiáo com $120 \mathrm{~m}$ de altitude apresenta médias anuais de temperatura e de precipitação de $25,3^{\circ} \mathrm{C}$ e $1245 \mathrm{~mm}$, respectivamente.

A área da APS é de 100 hectares, sendo que na época de colheita dos frutos o povoamento apresentava 17 anos de idade e densidade de 167 árvores.ha ${ }^{-1}$. O material de propagação utilizado para estabelecer o povoamento da Fazenda Paraguatuba foi procedente de outras duas APS da mesma empresa localizadas no Sítio Castiçal e na Fazenda Teca, sendo que esses dois povoamentos foram estabelecidos com diásporos importados de Trindade e Tobago, decorrente de um ensaio de procedência com material oriundo de "Tenasserim", Myanmar (Caldeira et al., 2000). 
O primeiro lote foi constituído de frutos colhidos imediatamente após a queda natural no dia 22 de junho de 2000, enquanto os frutos dos outros dois lotes haviam sido colhidos anteriormente no dia 06 do mesmo mês, após a queda precoce, ocasionada pela açáo de ventos fortes seguidos de precipitação. Após a colheita, os diásporos foram submetidos à secagem natural em ambiente de galpáo, ao beneficiamento para retirada do exocarpo e à homogeneização em peneira mecânica.

De cada lote foi retirada uma amostra de $5 \mathrm{~kg}$ de diásporos, a partir da qual foram determinados os valores iniciais de teor de água, massa de mil diásporos, número de diásporos por quilograma, uniformidade por classe de tamanho e emergência de plântulas ao $30^{\circ}$ dia (Brasil, 1992). Também foi determinado o número de sementes por fruto (KaosaArd, 1986) e o tempo médio de emergência de plântulas (Nakagawa, 1999).

O teor de água em base úmida foi determinado após a secagem em estufa a $105 \pm 3^{\circ} \mathrm{C}$ por 24 horas em quatro subamostras de 5g. A massa de mil diásporos foi determinada pela contagem manual de oito subamostras de 100 frutos, retirados ao acaso, que foram pesadas, e em seguida, calculado o valor médio, desvio padrão e coeficiente de variação. Com esse resultado também foi determinado o número de diásporos por quilograma. Essas mesmas oito subamostras foram utilizadas para determinar a uniformidade dos frutos, através da classificação por tamanho por meio da passagem sob agitação em peneiras com a dimensão de 19,0; 16,0; 12,5 e 9,0 $\mathrm{mm}$ de diâmetro de malha. Os diásporos retidos em cada peneira foram contados e os valores expressos em porcentagem (Brasil, 1992).

Para determinar o número de sementes por fruto foi utilizado o teste de corte, "cutting test", em 100 frutos divididos em cinco subamostras de 20 frutos (Kaosa-Ard, 1986). Após a imersão em água por uma hora os diásporos foram depositados dentro de receptáculos escavados em uma peça de madeira de modo que o ponto de inserção do pedúnculo ficasse no nível da extremidade do receptáculo. Os receptáculos, na forma de meia esfera, apresentavam o diâmetro compatível com as dimensões das malhas das peneiras utilizadas para a classificação por tamanho. Os diásporos foram cortados no sentido transversal na sua parte central (Figura 1) e as sementes foram contadas e o valor médio expresso em porcentagem de frutos sem sementes ou com uma a quatro sementes.

Para o ensaio de emergência de plântulas em viveiro foram utilizados 200 diásporos de cada lote, divididos em quatro repetiçôes. Os diásporos foram submetidos à imersão prévia em água corrente por 24 horas e depositados em canteiros contendo areia lavada, de modo que sua parte superior ficasse nivelada com a superfície da areia e a parte oposta, o ponto de inserçấo do pedúnculo, enterrada na parte mais profunda (Caldeira et al., 2001). Foram efetuados os registros diários considerando apenas a primeira emergência de uma plântula para cada diásporo, com cotilédones expandidos e normais e a presença dos primórdios do primeiro par de folhas, durante 30 dias (Caldeira et al., 2000). Com os valores diários foi possível calcular a porcentagem e o tempo médio de emergência de plântulas, esse último de acordo com a fórmula estabelecida por Edmond e Drapala citada por Nakagawa (1999).

Após o processamento e a avaliação inicial, o restante dos diásporos foi acondicionado em sacolas de polietileno e armazenado em ambiente refrigerado, cujos valores médios de temperatura e de umidade relativa foram de $20,3^{\circ} \mathrm{C}$ e $75,7 \%$, determinados por meio de aparelho termohigrógrafo. A cada 50 dias, até 331 dias após a colheita, os diásporos foram avaliados quanto à porcentagem e o tempo médio de emergência de plântulas, seguindo as metodologias anteriormente apresentadas.

O delineamento experimental utilizado foi o inteiramente casualizado em esquema fatorial de $3 \times 7$ (lotes e períodos). Os resultados foram submetidos à análise de variância, sendo que as médias das variáveis foram comparadas pelo teste de Skott-Knott a 5\%. Os resultados também foram submetidos à análise de regressão polinomial e elaborados gráficos com as equaçôes significativas e de maior coeficiente de correlaçâo para a porcentagem e o tempo médio de emergência de plântulas em função do período após a coleta dos diásporos. Para os cálculos estatísticos foi utilizado o software SISVAR (Ferreira, 2000).

\section{RESULTADOS E DISCUSSÃO}

Foi constatada diferença para todas as características iniciais dos diásporos entre o lote colhido após queda natural (testemunha) e aqueles colhidos após queda precoce (lotes $1 \mathrm{e}$ 2), sendo que esses dois lotes diferiram entre si apenas quanto ao teor de água e o tempo médio de emergência de plântulas (Tabela 1). Nos três lotes náo foi registrada a presença de sementes de outras espécies e a diferença quanto à pureza foi relacionada com a maior quantidade de material inerte presente na testemunha. Os valores registrados para a testemunha foram semelhantes àqueles apresentados por Caldeira et al. (2000).

Os diásporos da testemunha apresentaram maior teor de água que dos lotes 1 e 2, mas a massa de mil diásporos foi menor e isto refletiu na quantidade de diásporos por quilograma, $1526 \pm 37$ diásporos. $\mathrm{kg}^{-1}$ para a testemunha e de $1456 \pm 29$ e de $1445 \pm 15$ diásporos. $\mathrm{kg}^{-1}$, respectivamente para os lotes 1 e 2 (Tabela 1). Esses valores estão dentro da faixa de 900 a 1500 diásporos. .g $^{-1}$ verificados por Cáceres Florestal (1997). São semelhantes também ao valor médio de 681g para a massa de mil diásporos e equivalente a 1471 diásporos. $\mathrm{kg}^{-1}$, para 13 lotes de teca, obtidos por Caldeira et al. (2000), cujos valores variaram de 1405 a 1578 diásporos. $\mathrm{kg}^{-1}$. 
Tabela 1 - Pureza, teor de água (TA), massa de mil diásporos (MMD), número de diásporos por quilograma (NDK), emergência de plântulas (E) e tempo médio de emergência (TME) de diásporos de Tectona grandis colhidos a partir da queda natural (Testemunha) e da queda precoce pela ação de intempérie (Lotes 1 e 2). Cáceres-MT, 2000-2001. CV = coeficiente de variação (\%).

\begin{tabular}{|c|c|c|c|c|c|c|c|c|}
\hline Característica & \multicolumn{2}{|c|}{ Testemunha } & \multicolumn{2}{|l|}{ Lote 1} & \multicolumn{2}{|c|}{ Lote 2} & $\mathrm{~F}$ & CV \\
\hline Pureza (\%) & 99,7 & $b$ & 99,9 & $\mathrm{a}$ & 99,9 & $\mathrm{a}$ & 6,8 & 0,1 \\
\hline TA (\%) & 9,8 & a & 8,5 & c & 8,9 & $b$ & 88,3 & 1,5 \\
\hline MMD (g) ${ }^{(1)}$ & $655,5 \pm 24,3$ & $b$ & $686,9 \pm 19,8$ & $\mathrm{a}$ & $692,1 \pm 10,3$ & $\mathrm{a}$ & 8,7 & 2,8 \\
\hline NDK (un) (1) & $1526 \pm 37$ & $\mathrm{a}$ & $1456 \pm 29$ & $b$ & $1445 \pm 15$ & $b$ & 8,9 & 2,9 \\
\hline$E(\%)$ & 58,3 & $\mathrm{a}$ & 23,5 & $b$ & 17,5 & $b$ & 16,2 & 33,1 \\
\hline TME (dias) & 10,2 & $\mathrm{a}$ & 19,4 & $b$ & 22,6 & c & 56,5 & 9,7 \\
\hline
\end{tabular}

Valores seguidos de mesma letra minúscula na linha não diferem entre si pelo teste de Skott-Knott a 5\%. (1) médias provenientes de oito repetições.

A emergência inicial de plântulas da testemunha foi mais que o dobro daquela obtida nos lotes 1 e 2 e o tempo médio de emergência da testemunha foi cerca da metade do tempo de emergência dos outros dois lotes (Tabela 1). Os menores valores de emergência dos dois lotes em relação à testemunha podem estar relacionados com imaturidade das sementes, cujo armazenamento de reservas nutricionais, deve ter sido inferior ao necessário. Esse fato foi observado por Caldeira $e t$ al. (2000), que trabalhando com um lote de diásporos colhido de forma semelhante, verificaram a emergência de 30\%.

O teste de corte efetuado com os diásporos da testemunha que não emergiram comprovou que todos os diásporos apresentavam os quatro lóculos vazios. A Figura 1 ilustra a aparência dos frutos submetidos ao teste de corte.

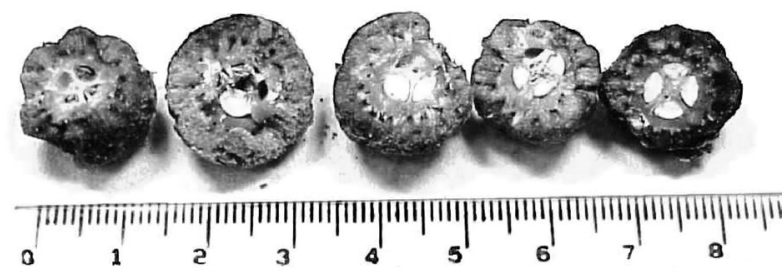

Figura 1 - Diásporos de Tectona grandis cortados transversalmente evidenciando a ausência de sementes e a presença de uma, duas, três ou quatro sementes. Cáceres-MT, 2000-2001.

A diferença na emergência de plântulas entre a testemunha e os lotes 1 e 2 se destacou quando se observa que a quantidade de diásporos sem sementes da testemunha é maior do que a quantidade dos lotes 1 e 2, e esses ainda apresentam maior quantidade de diásporos com 2, 3 e 4 sementes (Figura 2). $\mathrm{O}$ número de sementes por fruto foi semelhante para os três lotes, apenas para a freqüência de frutos com uma semente. A testemunha apresentou mais de $40 \%$ de frutos sem sementes, e para os lotes 1 e 2 os valores foram em torno da metade. Por outro lado, a testemunha apresentou menos de $12 \%$ dos frutos com duas sementes, e nos lotes 1 e 2 os valores foram mais que o dobro e esse fato foi semelhante para os frutos com três e com quatro sementes.

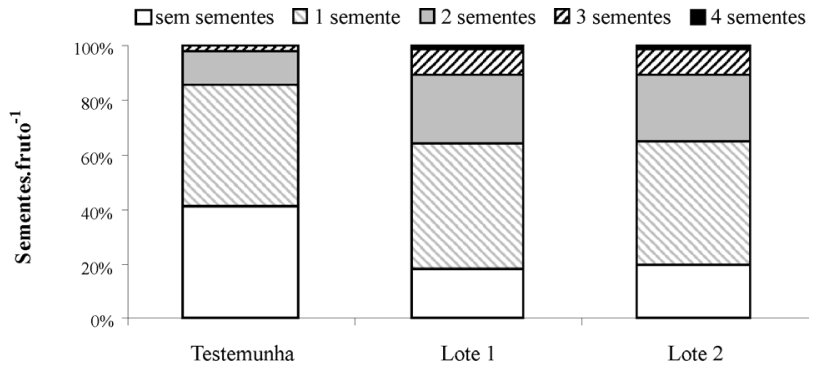

Figura 2 - Freqüência (\%) do número de sementes por fruto de diásporos de Tectona grandis colhidos após a queda natural (Testemunha) e após a queda precoce pela ação de intempérie (Lotes 1 e 2). Cáceres-MT, 2000-2001.

A este respeito, Banik (1977; 1978) trabalhou com 10.000 frutos em Bangladesh e concluiu que o número de sementes por fruto diminui com o decréscimo do tamanho dos frutos e que o tamanho do fruto é o principal fator para determinar o êxito na germinação apenas porque os frutos maiores apresentam maior quantidade de sementes. Contudo, essa característica não afeta a análise, pois sempre é considerada apenas a emergência de uma semente para cada diásporo. Bhumibhamon et al. (1983) náo encontraram correlação entre o tamanho da drupa e o número de sementes por drupa de frutos procedentes de cinco origens na Tailândia. Jayasankar et al. (1999) encontraram correlação negativa e baixa entre as características dos frutos de sete procedências e a porcentagem de germinação, enquanto Sivakumar et al. (2002) náo encontraram correlaçáo entre a massa de mil diásporos e a porcentagem de germinação, além de registrarem correlação negativa entre a germinação com a massa do mesocarpo ao estudarem sementes de 30 procedências de Bangladesh, Índia e Laos.

A uniformidade dos diásporos quanto às classes de tamanho foi semelhante para os três lotes (Figura 3). Em nenhum dos lotes foi observada a presença de diásporos com diâmetro superior a $19 \mathrm{~mm}$ ou inferior a $9 \mathrm{~mm}$. A maioria dos diásporos, 73 a 79\%, apresentou diâmetro entre 12,5 a $16,0 \mathrm{~mm}$, sendo esse valor um pouco menor do que o encontrado por Caldeira et al. (2000) para 13 lotes de diásporos, cuja média foi de $82,2 \%$. Kittinanda 
(1975) observou que a uniformidade dos diásporos varia mais quando são coletados em florestas naturais em relação às florestas plantadas, e registrou o diâmetro médio de 12 $\mathrm{mm}$ para um total de 59 procedências.

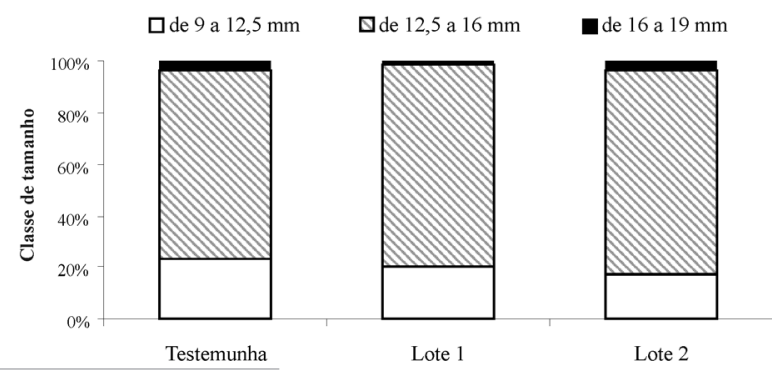

Figura 3 - Freqüência (\%) por classe de tamanho de diásporos de Tectona grandis colhidos após a queda natural (Testemunha) e após a queda precoce pela ação de intempérie (Lotes 1 e 2). Cáceres-MT, 2000-2001.

Nas Figuras 4 e 5 estão respectivamente os resultados de porcentagens de emergência de plântulas e os tempos médios de emergência de diásporos em função do período de armazenamento após a colheita. É possível verificar que os valores das duas variáveis, na testemunha, não diferiram em todos os períodos de análise. Por outro lado, para os lotes $1 \mathrm{e}$ 2 foram verificadas variaçóes ao longo dos períodos, mas com um comportamento semelhante entre os dois lotes.

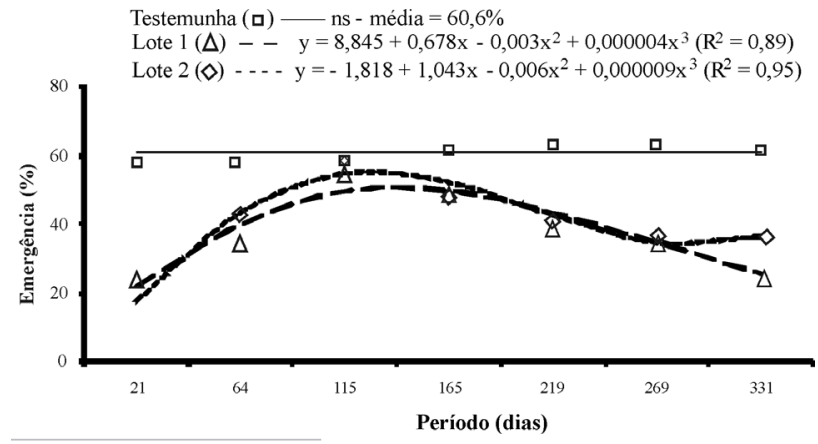

Figura 4 - Emergência de plântulas oriundas de diásporos de Tectona grandis em função do período após a queda natural (Testemunha) e da queda precoce pela ação de intempérie (Lotes 1 e 2). Cáceres-MT, 2000-2001.

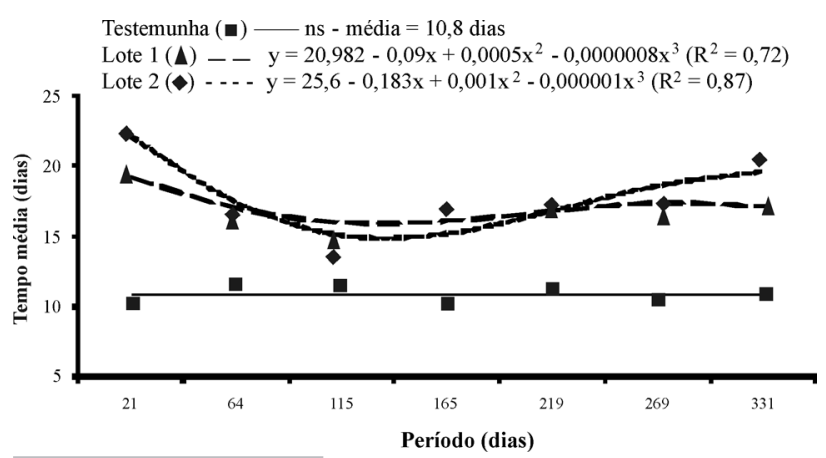

Figura 5 - Tempo médio de emergência de plântulas oriundas de diásporos de Tectona grandis em função do período após a queda natural (Testemunha) e da queda precoce pela ação de intempérie. Cáceres-MT, 2000-2001.
O maior valor de emergência de plântulas foi obtido aos 115 dias após a colheita para os lotes 1 e 2 e diferiu dos valores das avaliaçóes anteriores e posteriores a esse período, exceto para o lote 1 que manteve a porcentagem de emergência com 165 dias após a coleta (Figura 4). A comparação da emergência entre os três lotes em cada um dos períodos de análise revelou que a porcentagem de emergência de plântulas da testemunha foi superior a dos outros dois lotes em todos os períodos, exceto aos 115 dias, quando não diferiram entre si. Também não foi observada diferença dessa variável entre os lotes 1 e 2 . Esse comportamento coincide com informaçóes de Carvalho e Nakagawa (2000) de que as sementes que não atingiram a maturidade fisiológica e são colocadas para germinar logo após a colheita, mostram-se com menor porcentagem de germinação em relação àquelas cujos testes são realizados após o armazenamento.

Hedegart (1973) informou que os frutos de teca atingem seu tamanho máximo em aproximadamente 50 dias, mas não estão maduros até 120 dias após a fertilização e que um sinal de maturidade é que os frutos estejam caindo ao solo por si mesmo. Segundo Palupi e Owens (1998), o período de maturação da teca em Java é de 6 a 8 meses, sendo que o florescimento inicia em meados de janeiro até início de maio, em junho atingem o máximo de tamanho e a maturação ocorre de maio a setembro. Os autores informaram que o incremento em diâmetro dos frutos é rápido nas primeiras seis semanas após a antese e entre oito a 10 semanas atingem o máximo de diâmetro e a partir daí o diâmetro diminui suavemente até a $14^{\mathrm{a}}$ semana após a antese, à medida que o fruto começa a secar. Assim o comportamento observado pode ser decorrente do fato de que os diásporos apresentaram maturação após a sua colheita precoce.

Quanto ao tempo médio de emergência os menores valores para os dois lotes também foi registrado aos 115 dias após a colheita, indicando que neste período os diásporos apresentavam maior vigor (Figura 5). Contudo, de forma diferente da emergência de plântulas, quando se analisou essa variável dentro de cada período, ela sempre foi menor para a testemunha em relação aos dois lotes e esses variaram entre si na análise inicial e aos 331 dias. Esse comportamento pode ser observado com os resultados obtidos pela análise de regressão dos valores de porcentagem de emergência (Figura 4) e do tempo médio de emergência de plântulas (Figura 5). Para a testemunha, a análise de regressão comprovou o resultado obtido com a análise de variância para as duas variáveis, razão de ser apresentada uma semi-reta com o valor médio para expressar esse comportamento. Esse fato já havia sido registrado por Caldeira et al. (2003) que concluíram que a emergência dos diásporos armazenados até 12 meses em ambiente de sala $\left(28^{\circ} \mathrm{C}\right.$ e $61,7 \%$ de umidade relativa, UR) não foi diferente daqueles armazenados em câmara controlada por 
condicionador de $\operatorname{ar}\left(19,1^{\circ} \mathrm{C}\right.$ e UR de $\left.67,7 \%\right)$, e em relação ao valor da emergência inicial.

Para os lotes 1 e 2 as curvas foram significativas e as de maior coeficiente de correlaçâo foram todas de terceiro grau. Como era de se esperar o comportamento das curvas de porcentagem de emergência de plântulas (Figura 4) foi inverso ao das curvas do tempo médio de emergência (Figura 5). Assim, a porcentagem de emergência aumentou da avaliação inicial até 115 dias e, a partir daí, diminuiu até a análise dos 331 dias, enquanto o tempo médio de emergência diminuiu até 115 dias e a partir daí se estabilizou para o lote 1 até os 331 dias, enquanto para o lote 2 a estabilização foi até os 269 dias e aumentou aos 331 dias após a colheita.

Os resultados indicaram que o período de 115 dias após a colheita proporcionou a expressão do melhor potencial fisiológico em relação à quantidade de energia que pode ser acumulada até o momento da queda precoce. Esse valor é inferior à energia obtida na maturidade fisiológica que é o ponto em que a semente atinge o seu máximo de potencial fisiológico (Carvalho e Nakagawa, 2000). Castro et al. (2004) também mencionaram o efeito benéfico de curto prazo do armazenamento seco sobre sementes relativamente imaturas e a longevidade reduzida de tais sementes. Assim, existe a possibilidade de se utilizar este tipo de diásporo, pois, considerando o padrão mínimo de germinação estabelecido para a teca, de 35\% (Brasil, 1998b), os valores de emergência ultrapassaram esse valor dos 115 aos 269 dias, contudo, foram superiores aos outros períodos apenas aos 115 dias após a colheita (Figura 4).

\section{CONCLUSÕES}

Diásporos de teca colhidos após a queda natural apresentam maior potencial fisiológico em relação aos diásporos oriundos de colheita precoce pela queda por ação de intempérie, que apresentam maturaçáo após a colheita e o maior potencial fisiológico aos 115 dias.

O padrão mínimo estabelecido para a teca, $35 \%$, é atingido no período de 64 até 269 dias após a colheita, sendo o período mais adequado para a sua utilização de 115 a 165 dias. Nesse período a viabilidade pode ser semelhante àquela obtida com os diásporos de queda natural, contudo o vigor é inferior para aqueles lotes colhidos a partir da queda precoce pela ação de intempérie.

\section{AGRADECIMENTOS}

À empresa Cáceres Florestal SA e à Engenheira Florestal Pauline Annalore Kürten Tartari pelo apoio dado na conduçáo deste trabalho.

\section{BIBLIOGRAFIA CITADA}

Banik, R.L. 1977. Studies on grading of teak fruits. 1: Fruit size is a factor in germination of teak seeds. Bano Biggyan Patrika, 6: 1-7.

Banik, R.L. 1978. Studies on grading of teak fruits. 2: Combined effect of fruit weight and size in the production of seedlings. Bano Biggyan Patrika, 7: 20-29.

Bhumibhamon, S.; Ponoy, B.; Chaisurisri, K. 1981. Germination complex of teak fruits. Instituto Nacional de Investigaciones Forestales, Mexico. Publicación Especial, 35: 253-264.

Brasil, Ministério da Agricultura e Reforma Agrária. 1992. Regras para análise de sementes. Brasília, Distrito Federal: SNDA/DNDV/CLAV. 365 pp.

Brasil, Ministério da Agricultura. 1998a. Normas técnicas para produção de mudas fiscalizadas de espécies florestais. Cuiabá, Mato Grosso: DFA-MT. 60 pp.

Brasil, Ministério da Agricultura. 1998b. Normas técnicas para produção de sementes fiscalizadas de espécies florestais. Cuiabá, Mato Grosso: DFA-MT. 40 pp.

Cáceres Florestal. 1997. Manual do reflorestamento da teca. Cáceres, Mato Grosso: Cáceres Florestal SA. 31 pp.

Caldeira, S.F.; Caldeira, S.A.F.; Albuquerque, M.C.F. 2001. Comparação entre tratamentos pré-germinativos para análise de unidades de dispersão de teca, Tectona grandis L.F. Informativo ABRATES, 11: 272.

Caldeira, S.F.; Caldeira, S.A.F.; Albuquerque, M.C.F. 2003. Viabilidade de unidades de dispersão armazenadas de Tectona grandis. Associação Brasileira de Tecnologia de Sementes, 13: 371 .

Caldeira, S.F.; Caldeira, S.A.F.; Mendonça, E.A.F.; Diniz, N.N. 2000. Caracterizaçáo e avaliaçáo da qualidade dos frutos de teca (Tectona grandis L.f.) produzidos no Mato Grosso. Revista Brasileira de Sementes, 22: 216-224.

Carvalho, N.M.; Nakagawa, J. 2000. Sementes: ciência, tecnologia e produção. $4^{\mathrm{a}} \mathrm{ed}$. Jaboticabal, São Paulo: Funep. $588 \mathrm{pp}$.

Castro, R.D.; Bradford, K.J.; Hilhorst, H.W.M. 2004. Desenvolvimento de sementes e conteúdo de água. In: Ferreira, A.G.; Borghetti, F. (orgs.). Germinação: do básico ao aplicado. Porto Alegre, Rio Grande do Sul: ARTMED. p.51-67.

Ferreira, D.F. 2000. Análises estatísticas por meio do Sisvar para Windows versão 4.0. In: 45a Reunião Anual da Regiāo Brasileira da Sociedade internacional de Biometria. UFSCar, São Carlos, SP, Julho de 2000. p.255-258. Resumos... (www.dex.ufla.br/-danielff/softwares.htm). Acesso: 27/03/06. 
Figliolia, M.B.; Oliveira, E.C.; Pińa-Rodrigues, F.C.M. 1993. Análise de sementes, p.137-174. In: Aguiar, I.B.; Piña-Rodrigues, F.C.M.; Figliolia, M.B. coord. Sementes Florestais Tropicais. Brasília, Distrito Federal: ABRATES.

Guimarães, T.G.; Oliveira, D.A.; Mantovani-Alvarenga E.; Grossi, J.A.S. 1998. Maturação fisiológica de sementes de zínia (Zinnia elegans Jacq.). Revista Brasileira de Sementes, 20: 7-11.

Hedegart, T. 1973. Pollination of teak (Tectona grandis L.). Silvae Genetics, 22: 124-128.

Jayasankar, S.; Babu, L.C.; Sudhakara, K.; Unnithan, V.K.G. 1999. Provenance variation in seed and germination characteristics of teak (Tectona grandis L.F.). Seed Science and Technology, 27: 131-139.

Kaosa-Ard, A. 1986. Teak, Tectona grandis, Linn.f:: nursery techniques, with special reference to Thailand. (Seed Leaflet No. 4-A). Humlebaek, Denmark: Danida Forest Seed Centre. 42 pp.

Kittinanda, S. 1975. The handling and storage of teak seed, p.280-282. In: FAO/DANIDA Training Course on Forest Seed Collection and Handling, Rome: FAO, Forest Resources Div. (Report No. FAO-FOR-TF-RAS-11).

Musis, C.R. 1997. Caracterização climatológica da bacia do Alto Paraguai. Dissertação de Mestrado, Universidade Federal de Mato Grosso, Faculdade de Agronomia e Medicina Veterinária, Cuiabá, Mato Grosso. 65 pp.

Nakagawa, J. 1999. Testes de vigor baseado no desempenho das plantas. In: KRZYZANOWSKI, F.C.; VIEIRA, R.D.; FRANÇA NETO, J. B. Vigor de sementes: conceitos e testes. Cap. 2. Londrina, Paraná: ABRATES. 24 pp.
Palupi, E.R.; Owens, J.N. 1998. Reproductive phenology and reproductive success of teak (Tectona grandis L.f.). International Journal of Plant Science, 159: 833-842.

Piña-Rodrigues, F.C.M.; Aguiar, I.B. 1993. Maturação e dispersão de sementes, p.215-274. In: Aguiar, I.B.; PiñaRodrigues, F.C.M.; Figliolia, M.B. Sementes Florestais Tropicais. Brasília: ABRATES.

Shimizu, J.Y.; Klein, H.; Oliveira, J.R.V. 2007. Diagnóstico das plantaçôes florestais em Mato Grosso. Cuiabá, Mato Grosso: Central de Texto. 63 pp.

Sivakumar, V.; Parthiban, K.T.; Furudev Singh, B.; Gnanambal, V.S.; Anandalakshmi, R.; Geetha, S. 2002. Variability in drupe characters and their relationship on seed germination in teak (Tectona grandis L.f.). Silvae Genetics, 51: 232-237.

Suangtho, V. 2000. A study on teak seed germination effected of long-term storage methods. Lampang, Thailand: The Royal Forest Department of Thailand. 1p. (www.forest. go.th/Research/English/abstracts_silvic/seed.htm). Acesso: 06/12/06.

Recebido em: 04/08/2008

Aceito em: 25/05/2009 
ACTA

AMAZONICA

Potencial fisiológico de diásporos de Tectona grandis L.f. derrubados pelo vento 